\title{
FORMATION OF FOREIGN LANGUAGE COMMUNICATIVE COMPETENCE IN MEDICAL UNIVERSITY STUDENTS ON THE BASIS OF MODULAR RATING TEACHING TECHNOLOGY
}

\author{
Nadezhda A. Antonova ${ }^{1 \star}$, Margarita V. Emelyanova ${ }^{2}$, Tatiana S. Ignateva ${ }^{3}$ \\ ${ }^{1}$ Assoc. Prof., Chuvash State University, RUSSIA, nejda@rambler.ru \\ ${ }^{2}$ Assoc. Prof., Chuvash State University, RUSSIA, marg emel@yahoo.com \\ ${ }^{3}$ Assoc. Prof., Chuvash State University, RUSSIA, tatius67@yandex.ru
}

\begin{abstract}
The solution of important issues and problems in the field of medicine in the framework of international cooperation and exchange of best practices with foreign colleagues requires medical workers to have foreign language communicative competence.

This determines the relevance of research aimed at developing effective technologies for the formation of foreign language communicative competence among students of medical universities, taking into account the content of their future professional activities. One of these technologies is modular-rating technology.

The article provides a complex of pedagogical conditions of foreign language communicative competence formation among the medical universities students during the process of studying "Foreign language" based on module-rating technology. On the basis of theoretical analysis and generalization of scientific and methodological literature and their own experience in teaching the discipline "Foreign language" to medical students, the authors identified a complex of pedagogical conditions, the implementation of which within the framework of the modular-rating technology will provide, according to their assumption, a significant increase in the foreign language formation effectiveness.
\end{abstract}

For the practical substantiation of the implementation effectiveness of this pedagogical conditions complex in the process of teaching students the discipline "Foreign language" based on modular-rating technology, the authors organized and conducted a formative pedagogical experiment with the participation of 48 first-year students of the Medical Faculty of the I.N. Ulianov Chuvash State University. All students were divided into two groups - control and experimental. Control group students studied the discipline "Foreign language" within the framework of traditional approaches to teaching it in non-linguistic universities. The students of the experimental group studied this discipline based on modular-rating technology, taking into account the complex of the pedagogical conditions the authors identified. In the subjects of both groups, at the beginning and after the completion of the pedagogical experiment, the level of formation of foreign language communicative competence was determined using the diagnostic apparatus the authors developed. The indicators were measured: linguistic competence, characterizing the level of proficiency in phonetics, vocabulary and grammar of the target language; speech competence, reflecting the mastery of such types of speech activities as reading, writing, listening and speaking; sociocultural competence. The development level of each of the components of linguistic and speech competence and sociocultural competence as a whole was measured and assessed on a 100-point scale: students completed 25 test tasks, while the correct performance of each task was assessed at 4 points. Taking into account the results of the test tasks, the indicator of language and speech competence was calculated. The indicator of the foreign language communicative competence formation was determined as the arithmetic mean of the indicators of language, 
speech and sociocultural competencies.

The authors came to the conclusion that students of medical universities who teach the discipline "Foreign language" within the framework of traditional approaches to the educational process leads to a significant increase in the level of foreign language communicative competence formation. At the same time, traditional teaching predominantly ensures the subjects' mastery of vocabulary, speaking and writing. To a lesser extent, this is manifested in relation to phonetics and listening skills. Students of medical universities who teach the discipline "Foreign language" on the basis of the modular-rating technology implementation, taking into account the complex of the pedagogical conditions the authors identified, leads to a significant process efficiency increase of the foreign language communicative competence formation. At the same time, the modular-rating technology to the greatest extent contributes to the intensive subjects' mastery of vocabulary and listening, to a lesser extent - the mastery of grammar and reading.

Keywords: Foreign language communicative competence, language, speech, sociocultural competence, higher medical school, students, pedagogical conditions, module-rating technology of teaching.

\section{INTRODUCTION}

The inclusion of Russia in the Bologna process and entry into the Single European educational space led to a revision of the goals and results of teaching a foreign language in the system of higher professional education. The strategic goal is the formation of foreign language communicative competence, as the ability and readiness of a future human specialist to build interpersonal and business communication and interaction with other people, and the desired result is the readiness and ability to use a foreign language as a means of intercultural knowledge and communication (Antonova, Ignateva, 2015, P. 1214; Bykova, Kuvaldina et al., 2018, pp. 275-285; Ignateva, Antonova, 2016, pp.126-130; Strenadyuk, 2021, pp. 161-164).

The solution of important issues and problems in the field of medicine in the framework of international cooperation and exchange of best practices with foreign colleagues requires medical workers to have foreign language communicative competence (Ignateva, 2011, pp. 95-99).

This determines the relevance of research aimed at developing effective technologies for the formation of foreign language communicative competence among students of medical universities, taking into account the content of future professional activities (Zimina, Lyulyaeva, 2017, P. 150; Kareva, 2014, pp. 70-77; Yamskikh et al., (2014), pp. 70-77; Shmeleva, 2021, pp. 210-213). One of these technologies is modularrating technology.

On the basis of theoretical analysis and generalization of scientific and methodological literature and our own experience in teaching the discipline "Foreign language" to students of a medical university, we identified a complex of pedagogical conditions, the implementation of which within the framework of the modular-rating technology will provide, according to our assumption, a significant increase in the effectiveness of the formation of a foreign language communicative competence:

- Determining the structure of the goals of teaching a foreign language, taking into account the essence and content of foreign language communicative competence and the requirements of the Federal State Educational Standard of Higher Professional Education for its formation among graduates of medical universities (why should we teach?);

- Defining and structuring the content of teaching a foreign language into blocks, modules and private didactic units, the assimilation of which is necessary and sufficient for the formation of relevant competencies and foreign language communicative competence in general (what to teach?);

- Transforming the training content into a system of educational tasks for the organization of educational and cognitive activities of students, aimed at its assimilation;

- Using the information and communication technologies for the organization of educational and cognitive activities of students on the implementation of educational tasks, for operational, current, intermediate and final rating quality control of mastering the content of didactic units;

- Intensification of students' speech communication based on the use of interactive forms of teaching and a collective way of teaching with the dominant role of mutual learning in pairs of shift composition;

- Individualization of the goals, content and process of teaching students through the development of 
individual educational routes, taking into account the initial level of each foreign language communicative competence (Antonova, 2014, pp. 1087-1091).

\section{ORGANIZATION AND RESEARCH METHODS}

For a practical substantiation of the implementation effectiveness of this complex of pedagogical conditions in the process of teaching students the discipline "Foreign language" on the basis of modular-rating technology, we organized and conducted a formative pedagogical experiment with the participation of 48 first-year students of the Medical Faculty of the I.N. Ulianov Chuvash State University. All students were divided into two groups - control (16 students) and experimental (32 students).

The students of control group studied the discipline "Foreign language" within the framework of traditional approaches to teaching it in non-linguistic universities. The students of the experimental group studied this discipline based on modular-rating technology, taking into account the complex of the pedagogical conditions we identified.

In total, 64 hours were allocated for the study of this discipline in accordance with the curriculum.

In the subjects of both groups, at the beginning and after the end of the pedagogical experiment, the level of formation of foreign language communicative competence was determined using the diagnostic apparatus we developed. The indicators were measured: linguistic competence, characterizing the level of proficiency in phonetics, vocabulary and grammar of the target language; speech competence, reflecting the mastery of such types of speech activities as reading, writing, listening and speaking; sociocultural competence.

The development level of each of the components of linguistic and speech competence and sociocultural competence as a whole was measured and assessed on a 100-point scale: students completed 25 test tasks, while the correct performance of each task was assessed at 4 points.

Taking into account the results of the test tasks, the indicator of language and speech competence was calculated. The indicator of the formation of foreign language communicative competence was determined as the arithmetic mean of the indicators of language, speech and sociocultural competencies.

\section{RESEARCH RESULTS}

The data given in Table 1 indicate that the indicators of foreign language communicative competence among students of the control and experimental groups did not differ significantly at the beginning of the experiment, which indicates the relative homogeneity of both samples of subjects.

Table 1. Indicators of foreign language communicative competence among students before the pedagogical experiment, points $(X \pm \delta)$

\begin{tabular}{|c|c|c|c|c|}
\hline $\begin{array}{c}\text { Group of } \\
\text { students }\end{array}$ & $\begin{array}{c}\text { Language } \\
\text { competence }\end{array}$ & $\begin{array}{c}\text { Speech } \\
\text { competence }\end{array}$ & $\begin{array}{c}\text { Sociocultural } \\
\text { competence }\end{array}$ & $\begin{array}{c}\text { Foreign } \\
\text { language } \\
\text { communicative } \\
\text { competence }\end{array}$ \\
\hline $\begin{array}{c}\text { experimental } \\
\text { group }\end{array}$ & $40.21 \pm 4.23$ & $38.28 \pm 5.66$ & $38.44 \pm 9.54$ & $38.98 \pm 4.77$ \\
\hline $\begin{array}{c}\text { control } \\
\text { group }\end{array}$ & $42.71 \pm 3.89$ & $38.59 \pm 3.87$ & $38.75 \pm 7.19$ & $40.02 \pm 3.93$ \\
\hline$P$ & $>0.05$ & $>0.05$ & $>0.05$ & $>0.05$ \\
\hline
\end{tabular}

Attention is drawn to the relatively low level of foreign language communicative competence among students of both groups (38.98 and 40.02 points on a 100-point scale), which is due, in our opinion, to the low quality of teaching a foreign language in general education schools.

Comparative analysis of experimental data shows that the most developed among students of both the control and the experimental group is language competence ( 40.21 and 42.71 points). The indices of speech and sociocultural competence in the subjects of both groups were somewhat lower.

Table 2 shows the indicators of foreign language communicative competence among the subjects of the experimental and control groups after the pedagogical experiment. 
Table 2. Indicators of foreign language communicative competence among students after a pedagogical experiment, points $(X \pm \delta)$

\begin{tabular}{|c|c|c|c|c|}
\hline $\begin{array}{c}\text { Group of } \\
\text { students }\end{array}$ & $\begin{array}{c}\text { Language } \\
\text { competence }\end{array}$ & $\begin{array}{c}\text { Speech } \\
\text { competence }\end{array}$ & $\begin{array}{c}\text { Sociocultural } \\
\text { competence }\end{array}$ & $\begin{array}{c}\text { Foreign } \\
\text { language } \\
\text { communicative } \\
\text { competence }\end{array}$ \\
\hline $\begin{array}{c}\text { experimental } \\
\text { group }\end{array}$ & $70.52 \pm 9.73$ & $75.16 \pm 6.50$ & $74.69 \pm 5.67$ & $73.45 \pm 3.48$ \\
\hline control group & $48.33 \pm 4.04$ & $45.94 \pm 3.86$ & $44.38 \pm 5.12$ & $46.22 \pm 3.00$ \\
\hline$P$ & $<0.001$ & $<0.001$ & $<0.001$ & $<0.001$ \\
\hline
\end{tabular}

Comparative analysis of the indicators of language competence observed among students of the control group at the beginning and after the pedagogical experiment revealed their significant increase from 42.71 to 48.33 points. At the same time, the highest growth rates were observed in terms of vocabulary proficiency by 7.50 points (from 43.75 to 51.25 points). The growth rates of phonetics proficiency indicators were significantly lower - only 3.75 points (from 38.75 to 42.50 points). Indicators of grammar proficiency increased by 5.62 points (from 45.63 to 51.25 points).

The data given in Tables 1 and 2 indicate that the study of a foreign language led to a significant increase in the indicators of speech competence (from 38.59 to 45.94 points). The highest growth rates were observed in terms of proficiency in speaking - by 11.25 points (from 39.38 to 50.63 points) and in writing - by 10 points (from 38.75 to 48.75 points), the lowest - in terms of listening - by 3.75 points (from 40.63 to 44.38 points). The indices of reading proficiency increased by 4.37 points and amounted to 40 points after the completion of the pedagogical experiment.

The indicators of sociocultural competence improved by 5.63 points and amounted to 44.38 points at the end of the experiment.

Comparative analysis of the data showed that the growth rates of indicators of linguistic, speech and sociocultural competencies were approximately the same and amounted to 5.62 points, 7.35 points and 6.63 points, respectively.

The level of foreign language communicative competence among students of the control group increased by an average of 6.20 points (from 40.02 to 46.22 points). The differences are statistically significant at $P<0.01$.

Teaching students of the experimental group a foreign language on the basis of modular-rating technology, taking into account the complex of the pedagogical conditions we have identified, led to a more significant increase in the indicators of foreign language communicative competence.

In particular, the indicators of language competence increased by 30.31 points (from 40.21 to 70.52 points). The highest growth rates were observed in mastering vocabulary - by 42 points (from 43 to 85 points), the lowest - in mastering grammar - by 28.75 points (from 45.0 to 73.75 points). The phonetic skills improved by 35 points (from 38.44 to 73.44 points).

In addition, the students of the experimental group significantly improved the indices of speech competence - by 36.88 points (from 38.28 to 75.16 points).

The listening indicators improved most significantly - by 51.25 points (from 40.31 to 91.56 points), the lowest growth rates were observed in relation to reading skills - by 20.73 points (from 40.21 to 60.94 points).

Indicators of writing skills improved by 37.81 points (from 38.44 to 76.25 points), speaking -42.82 points (from 39.06 to 71.88 points).

Comparative analysis of the data also indicates a significant increase in indicators of sociocultural competence - by 36.25 points (from 38.44 to 74.69 points).

Due to the high rates of growth of indicators of language, speech and sociocultural competence among students of the experimental group, there was a significant increase in the level of formation of foreign language communicative competence as a whole - by 34.47 points (from 38.98 to 73.45 points). 
Comparing the indicators of foreign language communicative competence, revealed after the completion of the pedagogical experiment (Table 2), it should be emphasized that the students of the experimental group differed in relation to the students of the control group in higher indicators of the development of language competence (70.52 versus 48.33 points).

At the same time, they had a significant advantage in terms of vocabulary (85.0 versus 51.25 points), grammar (73.73 versus 51.25 points) and phonetics (73.44 versus 42.50 points). The differences are statistically significant at $\mathrm{P}<0.001$.

The data given in Table 2 also indicate a significant advantage of the students of the experimental group after the completion of the pedagogical experiment in terms of speech competence (75.16 versus 45.94 points). In particular, they had higher indices of proficiency in various types of speech activity: reading (60.94 versus 40.00 points), writing (76.25 versus 48.75 points), listening (91.56 versus 44.38 points) and speaking (71.88 vs. 50.63 points).

The level of formation of sociocultural competence among students of the experimental group after the completion of the pedagogical experiment was also higher than among students of the control group (74.69 versus 44.38 points at $\mathrm{P}<0.001)$. The students of the experimental group were distinguished by deep knowledge of the culture of the countries of the studied language, they could describe in detail the geographical location and climatic conditions, did not experience difficulties in the selection of lexical units in a certain sociocultural situation, they could convey information about the realities characteristic of a particular region.

The level of foreign language communicative competence among students of the experimental group after the completion of the pedagogical experiment was significantly higher than among students of the control group -73.45 versus 46.22 points at $P<0.001$.

\section{CONCLUSION}

Indicators of the foreign language communicative competence development and its individual competencies in first-year students are below average, which is due to the low quality of teaching a foreign language in a general education school.

Relatively low indicators of phonetics and reading skills distinguish first-year students that is due to insufficient attention on the part of secondary school teachers and schoolchildren to these sections of the "Foreign Language" academic discipline.

Teaching students of medical universities the discipline "Foreign language" within the framework of traditional approaches to the educational process leads to a significant increase in the level of the foreign language communicative competence formation. At the same time, traditional teaching predominantly ensures the subjects' mastery of vocabulary, speaking and writing. To a lesser extent, this is manifested in relation to phonetics and listening skills.

At the same time, the modular-rating technology to the greatest extent contributes to the intensive mastery of the subjects of vocabulary and listening, to a lesser extent - the mastery of grammar and reading.

Thus, teaching students of a medical university the discipline "Foreign language" based on the modularrating technology implementation, taking into account the complex of pedagogical conditions we identified, leads to a significant increase in the efficiency of the process of the foreign language communicative competence formation.

\section{REFERENCE LIST}

Antonova N. A. (2014). Foreign Language Communicative Competence Formation of Medical University Students Based on Module-Rating Technology of Teaching. Fundamental research, 9-5.

Antonova N. A., Ignateva T. S. (2015). About the Problem of Translation Adequacy of English Author's Tale. Modern problems of science and education, 1-1.

Bykova S.S., Kuvaldina E.A., Mashkovtseva L.M. and Malova T.V. (2018). Lessons for Developing Students' Communicative Competence, European Journal of Contemporary Education, vol. 7(2). 
Ignateva T. S., Antonova N. A. (2016). Teaching Medical Students to Understand and Translate Original Texts in a Specialty without a Dictionary. Improving the system of higher education: experience and prospects. Materials of the VIII International Educational and Methodical Conference.

Ignateva T.S. (2011). Diagnostics of the Moral Culture Level among First-Year Students of the Medical Faculty. Bulletin of I. Yakovlev Chuvash State Pedagogical University, 3-2 (71).

Kareva L.A. (2014). Selfguided Work of Nonlinguistic Training Course Students in Learning Foreign Language. Philology. Questions of theory and practice, 10-2 (40).

Shmeleva Z.N. (2021). Relevant Technologies of Teaching a Foreign Language in a Non-Linguistic University. Baltic Humanitarian Journal, vol. 10, 3 (36). DOI: 10.26140/bgz3-2021-1003-0053

Strenadyuk G. S. (2021). On the Question of Formation and Development of Philological Foreign Language Culture in the System of Additional Qualifications (axiological aspect). Baltic Humanitarian Journal, 3(36). DOI: $10.26140 / \mathrm{bgz3}-2021-1003-0039$

Yamskikh T.N., Slepchenko N.N. and Fukalova A.O. (2016). Pedagogical Design of Adaptability Algorithms for E-learning Course on English Grammar. Bulletin of the Krasnoyarsk State Pedagogical University, vol. 4 (38).

Zimina M.V., Lyulyaeva N.A. (2017). The Use of Information and Communication Technologies in the Teaching of Foreign Languages. Modern problems of science and education, 4. 